\title{
DELFIM SANTOS
}

(1908-1960)

\section{E A FENOMENOLOGIA}

\section{Carlos Morujão}

Universidade Católica Portuguesa

Não tendo nunca sido um fenomenólogo, Delfim Santos manteve uma relação de mais de três décadas com a fenomenologia, desde que, em 1935, assistiu à célebre conferência proferida por Husserl no Kulturbund de Viena, intitulada A Humanidade Europeia e a Filosofia. Cerca de 25 anos mais tarde, em dezembro de 1959, a sua conferência «A problemática fenomenológica de Husserl», constituiu um momento significativo da receção do pensamento fenomenológico em Portugal e, no conjunto da obra de Delfim Santos, talvez a única vez em que foi tentada uma apreciação de conjunto do significado da obra de Husserl. Mas o interesse de Delfim Santos pela discussão de temas fenomenológicos na Universidade Portuguesa pode também comprovar-se pela sua presença em júris de provas académicas em que os candidatos abordavam a fenomenologia husserliana, como foi o caso, em 1961, do doutoramento de Alexandre Fradique Morujão, na Faculdade de Letras da Universidade de Coimbra. Para além de Husserl, o interesse de Delfim Santos alargou-se ainda a outros vultos do movimento fenomenológico: Martin Heidegger (a quem dedicou alguns significativos ensaios), Max Scheler, Merleau-Ponty - este último presente, sobretudo, nos seus textos pedagógicos e de Filosofia da Educação - e, em menor medida, Sartre. Não é também de excluir que a sua crítica às teses do positivismo lógico do Círculo de Viena possa ter sido motivada, em parte, pelo contacto com a fenomenologia, embora a inspiração fundamental tenha vindo de Nicolai Hartmann. Em A Situação Valorativa do Positivismo nenhum autor diretamente ligado ao movimento fenomenológico é citado na extensa bibliografia final. É, contudo, em Conhecimento e Reali- 
dade, de 1940, que a relação com alguns temas da fenomenologia nos parece mais forte, como tentaremos demonstrar na $1 .^{\text {a }}$ Secção deste ensaio, embora a partir de uma problemática gnosiológica que se formula em termos que não são os de Husserl ou de Heidegger.

O que acabámos de dizer, porém, constitui uma dificuldade de não pouca monta na abordagem do pensamento de Delfim Santos, mesmo que a queiramos fazer apenas a partir do que não constitui nele mais do que um aspeto particular: a sua relação com a fenomenologia. É a partir da posição filosófica de Hartmann (que virá a conhecer pessoalmente em Berlim, no início dos anos quarenta do século passado) que o autor português aborda o significado da fenomenologia para a filosofia do século XX; por sua vez, a forte inspiração que Hartmann sempre representará para Delfim Santos está já direcionada para a resolução de uma problemática que terá surgido muito cedo na sua mente e a que não foi alheia a sua estadia em Viena, desde meados da década de trinta, como Bolseiro do Instituto de Alta Cultura: problemática que se formara já, provavelmente, nos seus anos de formação na primitiva Faculdade de Letras da Universidade do Porto, a partir do ensino de Leonardo Coimbra e do contacto com as suas obras. Relativamente a este assunto, é fundamental a leitura de um texto de 1959 intitulado «Leonardo Coimbra e a sua contribuição filosófica», incluído no Volume II das Obras Completas. ${ }^{1}$ Centrado numa análise de uma obra de Leonardo intitulada Razão Experimental, de 1923, todo o texto procura mostrar como nela se formula um conceito plural de experiência, solidário de uma distinção entre zonas de realidade que impossibilita que dos variados usos desse mesmo conceito se possa apresentar um denominador comum. ${ }^{2}$ Será, justamente, para a correta formulação de um tal conceito plural de experiência que a fenomenologia - nas suas diversas variantes e escolas - será por diversas vezes convocada na obra de Delfim Santos. Tentaremos ver, nas linhas que se seguem, com que pertinência o foi.

\section{Primeiras aproximações à fenomenologia de Husserl}

Num curto texto inédito não datado ${ }^{3}$ - mas destinando-se a uma conferência sobre o tema da objetividade, como o seu título e estilo indiciam Delfim Santos faz a seguinte afirmação: "Os sistemas filosóficos pressupõem

\footnotetext{
${ }^{1}$ Delfim Santos, Obras Completas (3 vols.). Lisboa: Fundação Calouste Gulbenkian, 2." ed.: 1982. De agora em diante, todas as referências às obras de Delfim Santos far-se-ão no corpo do texto, pela sigla OC, seguida, em números romanos, do tomo, e, em numeração, árabe, da paginação. O texto que mencionámos pode ler-se em OC II, 281-294.

2 OC II, 293.

${ }^{3}$ Incluído em OC II, 353-356.
} 
ou fundamentam tipos de objetividade não coincidentes, tal como acontece à atividade científica. $\mathrm{Na}$ atualidade, e a partir da fenomenologia de Husserl, o problema, embora indiretamente, tornou-se tema fecundo de investigação". ${ }^{4}$ Afirmação que ilustra exemplarmente, a nosso ver, as linhas de força da receção da fenomenologia por Delfim Santos (e, em particular, da husserliana) e o seu cruzamento com uma ontologia e uma teoria do conhecimento inspiradas, em boa medida, como já notámos, por Nicolai Hartmann.

Muitos aspetos do pensamento do filósofo português parecem aproximá-lo da fenomenologia. Em primeiro lugar, antes ainda do que poderíamos chamar as influências, que se revelariam no tratamento sistemático de esta ou de aquela questão, uma atitude geral perante o conhecimento que procura salvaguardar a existência de zonas distintas de realidade (com o seu eidos próprio, diria o filósofo de Freiburg), não reduzindo essa mesma realidade a uma explicação monista, ou seja, no fundo, metafisicamente já determinada, seja pelo idealismo, seja pelo realismo. Os $\S \S 9$ e 10 de Ideias para uma Fenomenologia Pura e uma Filosofia Fenomenológica, pelo menos, poderiam ser convocados para sustentar esta tese. ${ }^{5}$ Ora, para o pensador português, tanto o idealismo como o realismo esquecem a existência de um domínio prévio e articulado de objetivação, cujo reconhecimento é condição para que eles próprios possam fazer sentido enquanto explicações determinadas do modo de a ele aceder; ${ }^{6}$ aquilo, afinal, que a fenomenologia husserliana, a que Delfim Santos explicitamente se refere na passagem que acabámos de mencionar, reconhecia pelo termo de intencionalidade, cujo significado se encontra no famoso e nem sempre bem compreendido $\S 24$ de Ideias $I$, onde se enuncia o «princípio de todos os princípios» que orienta a atividade do fenomenólogo.

O problema central da fenomenologia - seja ela de inspiração husserliana ou não - é, defende o nosso autor em Conhecimento e Realidade, o estudo das formas variadas nas quais a realidade nos aparece, formas essas que nem sempre podem ser apreendidas pelos processos correntes de compreensão. ${ }^{7}$ Por isso, a intencionalidade husserliana não é já a de Franz Brentano, que procurava apenas um critério seguro para determinar a diferença entre objetos físicos e objetos psíquicos (recorrendo para tal à conhecida afirmação da

${ }^{4}$ OC II, 353 .

${ }^{5}$ De agora em diante, referir-nos-emos a esta obra de Husserl pela abreviatura Ideias I. Delfim Santos refere-se por diversas vezes a esta obra, mas quase sempre de uma forma genérica, às vezes indicando o título de uma secção (ou, eventualmente, de um capítulo) onde se aborda um determinado tema; por isso, as referências aos §§ serão sempre da nossa responsabilidade.

${ }^{6}$ OC II, 354.

${ }^{7}$ OC I, 281. Salvo indicação expressa da nossa parte em sentido contrário, sempre que reenviarmos para OC I, estaremos a referir-nos a Conhecimento e Realidade. 
«inexistência intencional», que seria própria dos segundo); nas próprias palavras de Delfim Santos, ${ }^{8}$ a fenomenologia é, antes de mais, o reconhecimento do trânsito entre o «pensamento do objeto» - o segundo situado numa zona de realidade que solicita o primeiro - e o «objeto do pensamento», quer dizer, reconhecido por este quanto ao seu sentido último e como pertencente, em cada caso, a uma região do real dotada da sua essência própria. Ultrapassando a distinção entre o real e o aparente, a fenomenologia separa-se das correntes filosóficas alemãs suas contemporâneas ${ }^{9}$ pelo facto de colocar em primeiro plano a análise do próprio critério valorativo que subjaz àquela distinção, interrogando, em primeiro lugar, o facto do «aparecimento», ${ }^{10}$ quer do que é tido como real, quer do que é tido como aparente, mas que, por isso mesmo, ainda aparece.

Já na conferência proferida em dezembro de 1959, que mais acima mencionámos, ${ }^{11}$ o sentido da fenomenologia e da sua situação no panorama filosófico da primeira metade do século XX é analisado a partir de uma perspetiva mais alargada. De certo modo, Delfim Santos entende que estava em jogo, com a obra de Husserl, uma reflexão de índole próxima da sua, sobre o papel da filosofia no mundo contemporâneo e a natureza da sua relação com as ciências mundanas ou ciências da atitude natural; ou, mais precisamente, não tanto com as ciências enquanto tais, mas antes com uma metafísica da ciência (mesmo que designada por positivismo), proclamando a supremacia do facto e reduzindo as essências a meras generalizações a partir de factos. A fenomenologia constitui, por isso, para o autor português, um elemento essencial do combate contra o positivismo, que apenas foi capaz de fornecer uma «solução indicativa» ${ }^{12}$ para o problema da realidade; tal solução, porém, pertinente quando se trata de saber o que é «isto» a que se dá um certo nome, torna-se incapaz de fornecer uma resposta satisfatória à investigação filosófica sobre o que seja a própria realidade, que se inicia, justamente, pelo reconhecimento de que «isto» é real. ${ }^{13}$ É assim que Delfim Santos afirma que, tendo começado por procurar fundamentar a matemática na filosofia, Husserl descobriu que era a

\footnotetext{
${ }^{8}$ OC II, 354.

${ }^{9}$ Delfim Santos entende por tal, quase sempre, o movimento neo-kantiano, relativamente ao qual, sempre que a ele expressamente se refere, não tem quaisquer palavras de apreço. Já quando menciona individualmente um ou outro representante da escola - Lask, por exemplo (OC I, 309), ou Windelband (OC I, 317) - a sua apreciação tem um carácter diferente. Cremos que Delfim Santos nunca terá conhecido a obra de Paul Natorp, que, tanto quanto sabemos, nunca cita, na qual poderia descobrir algumas afinidades com o pensamento husserliano.

${ }^{10} \mathrm{OC} \mathrm{I}, 283$.

${ }^{11}$ OC II, pp. 295-307.

12 É o título do $\S 23$ de Conhecimento e Realidade (OC I, 308).

${ }^{13}$ OC I, 308.
} 
própria filosofia que necessitava de fundamento, para se poder transformar em ciência absoluta e universal. ${ }^{14}$

\section{A fenomenologia e o problema da realidade}

Para vencer a ingenuidade das ciências mundanas, torna-se necessária uma descrição fenomenológica do ato de conhecimento. ${ }^{15}$ Uma descrição - e a expressão é tomada, diz Delfim Santos, no mesmo sentido em que se fala de geometria descritiva - não é apenas a fixação em palavras daquilo que é observado, mas sim uma fixação do objeto no seu quadro fundamental próprio, ${ }^{16}$ pondo entre parênteses aquilo que nele é acessório, ou relevando apenas de circunstâncias particulares contingentes; ora, se esse objeto, ou tema de estudo, é a relação cognitiva, o seu quadro próprio, aquele que nos garante que é de conhecimento e não de outra coisa que estamos a falar, é constituído por uma relação dual inultrapassável, nunca redutível a uma identidade, entre aquele conhece e o que é conhecido. Querer suprimir tal relação, pensar a identidade como algo mais do que o termo inalcançável do esforço de conhecimento, é dotar o espírito humano de capacidades que lhe não são próprias, como o tentaram fazer os sistemas do idealismo clássico. Por isso, mesmo quando Husserl fala de intuição (por exemplo, na sua conhecida referência à possibilidade de uma intuição das essências), não visa um conhecimento sem mediação de uma realidade exterior ao pensamento, que abolisse aquela dualidade, ${ }^{17}$ mas sim uma determinação as relações de carácter imanente, ou ideal, que são constitutivas do objeto. ${ }^{18}$

${ }^{14}$ OC II, 298.

${ }^{15}$ A utilização da expressão «descrição fenomenológica», no título do $\S 20$ de Conhecimento e Realidade (OC I, 303), releva de uma conceção do que seja a prática da fenomenologia mais próxima do pensamento de Hartmann do que do de Husserl. Não entraremos na discussão deste assunto, supondo-o, nos seus traços gerais, do conhecimento do leitor.

${ }^{16}$ OC I, 304.

${ }^{17} \mathrm{Em}$ 1938, ao publicar $A$ Situação Valorativa do Positivismo, Delfim Santos não parece conhecer a polémica entre Moritz Schlick e Edmund Husserl acerca da possibilidade de um conhecimento intuitivo. De facto, o ensaio de Schlick dirigido contra Husserl, intitulado «Gibt es ein intuitives Erkenntnis?», não é mencionado entre as diversas obras de Schlick citadas na bibliografia final. Contudo, a posição de Schlick sobre este problema é caracterizada com muita correção, a partir do que o filósofo vienense diz noutras obras suas acerca do mesmo assunto (OC I, 94-96). Delfim Santos nota que Schlick defende o carácter conceptual e não-intuitivo de todo o conhecimento, negando ainda que, mesmo existindo um hipotético contacto direto com a realidade, tal contacto fosse um conhecimento, constituindo antes uma variedade de experiência vital. Para Schlick, conhecimento intuitivo é, pura e simplesmente, uma contradictio in adjeto.

${ }^{18}$ OC I, 349. 
O idealismo de Husserl, como parece defender a Conclusão de Conhecimento e Realidade, ${ }^{19}$ foi sobretudo de natureza gnosiológica e, por isso, a sua exclusão da realidade exterior teve carácter metodológico, não constituindo nenhuma tese cosmogónica. Não existiu, por isso, nenhuma contradição entre o ponto de partida realista da fenomenologia e o idealismo proclamado por Husserl, em 1913, em Ideias I. A questão da existência ou não-existência da realidade exterior ao pensamento é desprovida de interesse para um idealismo de tipo husserliano, pois a sua exclusão visa apenas libertar o terreno para a análise da suposição primeira de todo o realismo ingénuo, a saber, a pretensa identidade absoluta entre o que é dado ao sujeito e a realidade que está na origem do dado.

Por isso, o sujeito do conhecimento, capaz de atingir formas lógicas de ordem essencial, não equivale ao sujeito empírico, cujos atos a atitude psicologista tenta descrever. Há que distinguir, portanto, entre o empírico e o transcendental. Em «A problemática fenomenológica de Husserl», Delfim Santos define a consciência transcendental como a criadora de possibilidades de atribuir sentido, tal como acontece, aliás, na relação da consciência empírica com a realidade exterior. ${ }^{20}$ A separação fenomenológica entre a consciência e o real - continua o filósofo português - é idêntica à que se operou entre a matemática, como criação do espírito humano, e o real, para que este pudesse ser organizado como mundo físico. ${ }^{21} \mathrm{Em} 1961$, num Curso de Extensão Universitária sobre Energia Nuclear, numa palestra intitulada «Significação filosófica da nova teoria da ciência», ${ }^{22}$ Delfim Santos faz uma curiosa aproximação. Assim como a teoria dos espaços abstratos, criada pelos matemáticos, foi elaborada antes da nova física, da mesma forma - afirma -, a exploração da atividade originária e constituinte da consciência iniciou-se também antes dela, com a fenomenologia de Husserl, que estuda geneticamente as categorias de espaço, tempo, coisa, objeto, e a sua correlação com a consciência pré-empírica ou transcendental. ${ }^{23}$

A fenomenologia assume, assim, o carácter de uma lógica transcendental, uma vez que se apresenta como o estudo dos processos de constituição do objeto e do seu sentido. ${ }^{24}$ A ela se fica a dever uma teoria da experiência (que o filósofo português quer aproximar, pelo menos nas suas intenções, da

\footnotetext{
${ }^{19}$ OC I, 339 e ss.

${ }^{20}$ OC II, 298.

21 OC II, 299.

22 OC II, 308-325.

${ }^{23}$ OC II, 324.

${ }^{24}$ OC II, 302.
} 
que se pode encontrar também em Leonardo Coimbra; ${ }^{25}$ que procura esclarecer os diferentes aspetos da realidade e os níveis diferenciados desta, libertando-a da sua radicação a uma única região da realidade - a do «percecionável sensorialmente» ${ }^{26}$ - que pretende subsumir todas as outras, como dotadas de menor valor. Inaugura-se, com a atitude fenomenológica, uma reflexão sobre a própria consciência na atividade constitutiva de si própria e constitutiva do sentido do mundo. ${ }^{27}$

Tal como Husserl, Delfim Santos reconhece o carácter não suficientemente radical do ponto de partida cartesiano; Descartes preocupara-se com o que resultava da sua descoberta do cogito, ou seja, com a árvore do saber $\mathrm{e}$ a sua descoberta é aferida em função de critérios provindos, ou das ciências físico-matemáticas, uma vez que, em sua opinião, só a sua metafísica poderia fundamentar a nova física (e a ação do homem sobre o mundo que ela veio possibilitar), ou da veracidade divina, uma vez que só esta, garantindo ao cogito algo mais do que a sua certeza sobre si mesmo, o assegura da existência de um mundo de corpos. ${ }^{28}$ A atitude de Descartes, ao contrário da de Husserl, não é transcendental, uma vez que o seu objetivo não é regredir até ao fundamento último do saber, mas sim progredir a partir do cogito em direção aos saberes já constituídos.

\section{Delfim Santos e Heidegger}

Tentámos, noutro local, ${ }^{29}$ chamar a atenção para o carácter não heideggeriano do pensamento existencial de Delfim Santos, procurando aproximá-lo,

${ }^{25}$ A questão é talvez de escasso interesse, tanto mais que Leonardo Coimbra conheceria Husserl apenas através da obra de Emmanuel Lévinas La Théorie de l'Intuition dans la Phénoménologie Husserlienne, que terá lido pouco após a sua publicação e de que se podem notar ecos no que é dito sobre Husserl, em 1935, em A Rússia de Hoje e o Homem de Sempre. Leonardo Coimbra formula uma teoria da experiência, cuja versão mais acabada se pode encontrar em A Razão Experimental, a que nos referimos já, profundamente devedora de autores anteriores à fenomenologia e alheios à própria tradição em que ela se insere, como foram os casos de Émile Boutroux e Renouvier ( $c f$. OC II, 293).

${ }^{26}$ OC II, 293.

${ }^{27}$ OC II, 303.

${ }^{28}$ OC II, 301.

${ }^{29}$ Cf. Carlos Morujão, "Delfim Santos, Hartmann e Heidegger”. In: Cristiana Soveral (Org.), Delfim Santos e a Escola do Porto. Lisboa, Imprensa Nacional-Casa da Moeda, 2008, pp. 171-182, pp. 172 e 182. Não sabemos ao certo quando terá Delfim Santos tido conhecimento do pensamento de Heidegger, mas já em 1938 revela conhecer textos seus, ao escrever o ensaio «Heidegger, Hölderlin e a essência da poesia». Em OC II, 357-369 transcreve-se um texto não datado (a que falta, como notam os editores, a primeira página), intitulado simplesmente «Heidegger», que consiste, no essencial, num resumo das principais teses de Ser $e$ Tempo. Miguel Real, em "A génese do existencialismo em Portugal" (in: Cristiana Soveral, 
por exemplo, do de um Karl Jaspers, com o qual tantas afinidades nos parece ter. Tal como o homem de Jaspers (e ao invés do Dasein heideggeriano), o homem para Delfim Santos é um existente sem existência, ou seja, sem um ser que o preceda, caindo na angústia sempre que busca na existência um ser que ela não tem. O pensador português, aliás, em «Jaspers na Filosofia Contemporânea», nota com clareza a matriz kierkegaardiana do pensamento existencial de Jaspers, não tanto por aquilo que ele tem de cristão - Delfim Santos, aliás, apoiando-se em Paul Ricœur e em Régis Jolivet, recusa a designação de «existencialismo cristão» -, como pelo reconhecimento de que categorias metafísicas como ser e essência são desadequadas para falar da existência, exigindo-se, por isso, categorias de um novo tipo. ${ }^{30}$

Certamente que esta posição nos faz recordar os existenciais heideggerianos, também eles diferentes das categorias clássicas da ontologia, ou seja, das categorias do ente em geral, e o pensamento de Heidegger não acusa menos do que o de Jaspers a consciência da necessidade de uma ultrapassagem da ontologia herdada para pensar a existência humana no que ela tem de mais próprio. Os existenciais heideggerianos são como que as categorias da existência de um ente (o Dasein) em cujo ser se inscreve a preocupação pelo sentido do ser em geral, sendo em função deste que o Dasein pode ser objeto de uma analítica, tal como a que foi levada a cabo na 1. ${ }^{2}$ Secção da $1 .{ }^{a}$ Parte de Ser e Tempo.

Mas já a própria utilização do termo Dasein, por Delfim Santos, parece mais próxima do significado deste termo em Jaspers do que em Heidegger. Embora seja arriscado afirmar-se que o autor português compartilha as teses do autor cujo pensamento comenta, no ensaio que mencionámos mais acima, não parece difícil encontrar alguma correspondência entre as respetivas filosofias. A distinção jaspersiana entre três espécies de ser - o ser que eu conheço, o ser que eu sou e o ser desconhecido, da metafísica tradicional - parece encaixar-se demasiado bem na tese do autor de Da Filosofia segundo a qual a realidade se estratifica em diversos níveis, cada um dos quais possuidor de um modo de ser próprio irredutível a um conceito genérico de ser. ( $\mathrm{O}$ qual Delfim Santos, por outro lado, parece detetar em Heidegger. ${ }^{31}$ No manuscrito

ob. cit., pp. 199-234, p. 206), afirma que o texto é seguramente da década de trinta, destinando-se, eventualmente, apenas a uso pessoal. Provavelmente o autor possui informação sobre o assunto a que não tivemos acesso, mas nada nos impede de pensar que a data aproximada que propõe esteja correta; aliás, Conhecimento e Realidade, de 1940, foi, segundo palavras do próprio Delfim Santos, «fruto do contacto direto de alguns anos com as novas correntes filosóficas representadas por Nicolai Hartmann e Martin Heidegger» (OC I, 277).

${ }^{30}$ OC II, 268-269.

${ }^{31}$ Cf. OC II, 276. 
intitulado «Heidegger», ${ }^{32}$ Delfim Santos vai ao ponto de afirmar que, na perspetiva heideggeriana, os entes possuem menor generalidade do que o ser, $o$ que parece confirmar o que dissemos.) Além disso, ao passo que uma das teses centrais de $\operatorname{Ser}$ e Tempo é que o Dasein é o ente que eu próprio sou e, ao mesmo tempo, algo que é em cada caso meu, Jaspers e Delfim Santos recusam a identificação entre o meu eu e o Dasein, na medida em que o projeto que é constitutivo da natureza do homem é, antes de mais, transcensão da situação (e não apenas projeto, como em Heidegger, remetendo para uma subjetividade objetivada) pela experiência de situações-limite..$^{33}$

Há, contudo, aspetos do pensamento heideggeriano que Delfim Santos valoriza, mas sempre numa perspetiva em que, ora a ontologia de Hartmann, ora a filosofia existencial de Jaspers, nos parecem assumir papel mediador. Ou seja, é através de temas do pensamento destes dois autores que certos temas de Martin Heidegger, reinterpretados a uma luz que nem sempre nos parece ser a sua, são valorizados pelo pensador português. Assim, por exemplo, em «Temática Existencial», ${ }^{34}$ considera Delfim Santos que tudo o que de unilateral possa ter existido, quer no essencialismo, quer no existencialismo, é ultrapassado por uma filosofia como a de Heidegger, que coloca no centro das suas preocupações a investigação sobre o «ser do ente», ${ }^{35}$ em que na própria terminologia se evidencia a estreita correlação entre um conteúdo e o ato pelo qual ele se atinge; por outras palavras, entre dois aspetos da realidade que se não excluem e que, tanto o essencialismo, como o existencialismo tomaram apenas unilateralmente como tema de investigação. Já em Da Filosofia a distinção heideggeriana entre ser e ente era utilizada com propósitos idênticos. O conhecimento dos entes é, nesta obra, designado por «conhecimento existencial», ${ }^{36}$ ou seja, conhecimento de uma zona da realidade em que certas categorias como o mecanicismo, o formalismo, ou o substancialismo podem ter a sua validade, perdendo-a, contudo, sempre que se pretenda realizar a sua extensão a outras zonas. É aqui que a «diferença ontológica» (Delfim Santos

32 OC II, 358.

${ }^{33}$ Que, para Heidegger, o ser do Dasein é, em cada caso, o meu, era algo que Delfim Santos sabia muito bem. Tal facto é explicitamente posto em evidência no texto que citámos linhas mais acima ( $c f$. OC I, 359). O que, por conseguinte, afirma do Dasein em contextos em que não está em causa a filosofia de Martin Heidegger não é uma projeção de teses heideggerianas mal compreendidas; pelo contrário, parece-nos a nós constituir um efetivo afastamento relativamente à posição de Heidegger sobre este assunto.

${ }^{34}$ OC II, 79-85.

${ }^{35}$ A expressão alemã é Sein des Seienden. Delfim Santos traduz por «ser do sendo» (cf. nomeadamente OC II, 80), mas nós preferimos utilizar a expressão consagrada na terminologia filosófica portuguesa.

${ }^{36}$ OC I, 232. 
não utiliza contudo, esta expressão) entre ser e ente revela toda a sua pertinência: ela impede que as categorias de um determinado tipo de realidade sejam transpostas para um outro onde manifestamente se não aplicam, como se tais categorias - para além do seu natural carácter ôntico, que é sempre «regional» - caracterizassem o próprio ser. Este é, diz o filósofo português, o procedimento habitual dos monismos de todos os tipos, cujo erro é a consequência de uma «ausência de critérios na limitação dos diferentes plurais que constituem a realidade». ${ }^{37}$

Este é, provavelmente, o tema mais forte e mais constante em toda a obra de Delfim Santos: a necessidade de constituição de um pensamento categorial, por meio do qual as linhas estruturais do mundo material, do mundo da vida, do mundo da consciência e do mundo do espírito (o que o nosso autor chama a ratio essendi de cada um deles), ${ }^{38}$ sejam captadas na sua especificidade. Se tais linhas são quase evidentes nos planos da matéria e da vida - e ciências como a física, a biologia e a química são disso a prova - já diante do plano da consciência nos encontramos na presença de uma série estrutural de ordem mais elevada e complexa, de um plano de existência imanente, impossível de reduzir estruturalmente às regiões da matéria e da vida, mesmo que delas não esteja nunca completamente separado. Superior a ela encontramos a região do espírito, que é essencialmente coexistência e comunicação. Consciência e espírito não são, por isso, o mesmo para Delfim Santos. Distinguem-se na medida em que a primeira é uma atividade de criação de formas para registo do que acontece nos planos da matéria e da vida, e relação imanente consigo mesma enquanto atividade criadora de tais formas, ao passo que o espírito é a capacidade de libertação em relação às esferas inferiores da realidade e de ligação entre os homens numa esfera de compreensão recíproca. ${ }^{39}$

${ }^{37}$ OC I, 233.

${ }^{38}$ Cf. Da Filosofia, OC I, 252-253.

${ }^{39}$ Arriscaríamos a afirmação de que as páginas de Da Filosofia que estamos a comentar foram escritas sob a forte influência de Max Scheler, em particular da sua última obra Die Stelling des Menschen im Kosmos (1928). As semelhanças são demasiado evidentes para quem conhece esta obra de Scheler, mas, na ausência de qualquer indicação expressa da parte do autor (que, habitualmente, não oculta as suas fontes de inspiração), não podemos mais do que formular uma mera suspeita. A mencionada obra de Scheler é citada por Delfim Santos em Fundamentação Existencial da Pedagogia, de 1946, mas em contexto totalmente diferente (OC II, 439). Reconhecemos ainda que tudo o que dissemos acima sobre esta matéria é demasiado esquemático, arriscando-nos mesmo a fornecer uma imagem empobrecida do pensamento de Delfim Santos sobre este assunto. Mas maiores desenvolvimentos sobre a sua reflexão (levada a cabo sob os auspícios de Hartmann, Hegel e Leonardo Coimbra) não têm lugar neste ensaio, dada que nos interessa apenas a relação de Delfim Santos com a fenomenologia. 
Mas também na abordagem dos temas propriamente existenciais - no sentido que esta palavra adquiriu com as filosofias chamadas existencialistas, no século XX - a influência de Martin Heidegger se volta a fazer notar. Ainda em «Temática Existencial», ao defender que a filosofia existencial é uma filosofia transcendental (mas que transformou em fim aquilo que - ou seja, o próprio homem - era, para Kant, um meio de apreensão da transcendência), fá-lo dizendo que tal acontece na medida em que todo o existencialismo busca determinar o ser do homem enquanto determinado na sua vida terrena pela transcendência, a qual constitui a estrutura fundamental da subjetividade. É patente, nestas páginas de Delfim Santos, a influência do ensaio heideggeriano de 1928 intitulado Sobre a Essência do Fundamento.

Em «Temática Existencial», contudo, a influência de Martin Heidegger faz-se ainda sentir noutras direções. Nota Delfim Santos que as modernas filosofias da existência acentuaram a aspiração constante do homem a sair do tempo e de si mesmo. Que é que provoca, no homem, esta aspiração? Heidegger respondera, como se sabe, numa Conferência de 1929 intitulada «Que é a Metafísica?», que tal se ficava a dever à presença do «nada». ${ }^{40}$ Indeterminado e transobjetivo, e, por isso mesmo, inapreensível pelo pensamento lógico, situado no plano teórico da compreensão, este nada, diz o filósofo português, é o sentimento resultante da negação da totalidade do ente; algo cuja presença - Delfim Santos recorre, agora, às palavras de Kierkegaard - o homem pode sentir quanto mais humano é, ${ }^{41}$ ou seja, quanto mais a consciência da sua finitude, do carácter transiente da sua existência mundana, da responsabilidade da sua passagem sobre a Terra, passa para primeiro plano, sobrepondo-se à relação com os entes.

Mas cremos ser ainda na linguagem de Jaspers, desprovida do pathos existencial heideggeriano e na qual os aspetos «decisionistas» do existir - toda a temática do projetar, que ocupa um lugar central em Ser e Tempo-passam para segundo plano, que aquela transiência do ser-no-mundo é expressa por Delfim Santos. O já estar no mundo (a Geworfenheit heideggeriana) e o ainda estar no mundo (o constante adiamento da morte) são, para o pensador português, aquelas situações-limite entre as quais tudo acontece e o próprio conhecimento é possível. ${ }^{42}$

${ }^{40}$ Em OC II, 82-83, onde discute este problema, Delfim Santos distancia-se da posição de Rudolf Carnap no pequeno ensaio - de resposta à mencionada Conferência de Heidegger intitulado "Superação da Metafisica pela análise lógica da linguagem", publicado na revista Erkenntnis. Carnap não é citado em "Temática Existencial", mas Delfim Santos conhecia o texto do filósofo alemão, que cita na bibliografia de Situação Valorativa do Positivismo (OC I, 190) (cf. Da Filosofia, OC I, 252-253).

${ }^{41}$ OC II, 83.

${ }^{42}$ OC II, 360. 


\section{Delfim Santos e o pensamento existencial de matriz fenomenológica}

A presença de Martin Heidegger é ainda patente noutro plano da reflexão de Delfim Santos. Referimo-nos a Fundamentação Existencial da Pedagogia, obra com a qual obtém o grau de Doutor em Filosofia pela Faculdade de Letras da Universidade de Coimbra. A Pedagogia enquanto ciência - afirma -, radica numa compreensão temporal da existência do homem, que se não limita a viver, mas que antes de mais existe, em contacto, simultaneamente, com os seres inanimados, com os outros seres vivos e consigo mesmo. $\mathrm{O}$ sentido existencial da relação com estes três constituintes do mundo é radicalmente diferente: ${ }^{43}$ o homem ocupa-se com as coisas, preocupa-se com os outros e preocupa-se consigo. Nesta distinção entre o «ocupar-se» e o «preocupar-se» não seria difícil encontrar a conhecida distinção entre Besorgen e Für-sorge, de que nos fala Ser e Tempo. Ora, desta diferença - diz o pensador português - resultam situações diferenciadoras do ponto de vista da aprendizagem; o homem compreende o «para» que está no mundo a partir de um diálogo com as coisas e com os outros, interrompido, frequentemente, pelo diálogo interior que trava consigo mesmo, pelo que, para a pedagogia, haverá três modos irredutíveis de desenvolver vocacionalmente as aptidões de cada indivíduo. ${ }^{44}$

Aprender transforma-se, assim, no «ato primário consequente do estarno-mundo» ${ }^{45}$ mundo esse que não é um conjunto de objetos inertes, dotados de uma existência em si, mas sim o que Delfim Santos chama uma totalidade de «coisas-para». Tais coisas não são, propriamente, antes resistem e, uma vez vencidas na sua oposição, transformam-se em ferramenta para vencer novas resistências. ${ }^{46}$ Elas também não são, por isso, meros objetos de uma contemplação mais ou menos desinteressada, mas sim utensílios vistos em função de uma obra que se planeou realizar, através de uma faculdade percetiva que pode ser educada tendo em conta a compreensão do «para que» se está no mundo. ${ }^{47}$ Isto mesmo é comprovado pela psicologia da forma, de cujos desenvolvimentos contemporâneos Delfim Santos dá mostra de conhecimento aprofundado; todo o ato percetivo supõe uma capacidade seletiva que aumenta a

${ }^{43}$ OC II, 440.

${ }^{44}$ OC II, 441.

${ }^{45}$ OC II, 441.

${ }^{46}$ Sobre tudo isto, pode consultar-se o $\S 16$ de Ser e Tempo, em que o autor claramente se inspira, inclusivamente no tipo de exemplos apresentados para fazer ressaltar o carácter «instrumental» e não «objetivante» dos entes intramundanos.

${ }^{47}$ Em OC II, 441, nota 21, Delfim Santos remete para Fenomenologia da Perceção de MerleauPonty, obra publicada em 1945, ou seja, no ano anterior à publicação de Fundamentação Existencial da Pedagogia, o que comprova a informação filosófica muito atualizada do pensador português. 
acuidade dos órgãos sensoriais, orientados para aperceber, na realidade confusa, os aspetos de maior ou menor interesse em função do projeto existencial. Uma perceção subordinada à dinâmica do interesse: tal é, para Delfim Santos, o ponto de contacto entre a moderna psicologia e uma fenomenologia existencial orientada para a análise do ser-no-mundo. A perceção humana não está, assim, exclusivamente guiada pela situação presente, antes constitui a manifestação de livre e espontânea criação de uma ordem espacial e temporal, distinta da que é inerente ao comportamento animal. ${ }^{48}$

O capítulo III de Fundamentação Existencial da Pedagogia intitula-se, significativamente, «A estrutura do comportamento» e é nele que a influência de Merleau-Ponty - tal como a dos psicólogos da Gestalt, interpretados por Merleau-Ponty, Koffka em particular - se revela com mais força. Criticando a ideia pavloviana de que todo o comportamento é a resposta a uma excitação, ${ }^{49}$ Delfim Santos, citando o filósofo francês, mostra como a própria excitação é já um início de resposta, o primeiro ato de funcionamento do organismo, em face de um agente físico-químico que, mais do que ser uma causa, constitui uma ocasião. Por isso, à teoria do reflexo condicionado, formulada pelo fisiologista russo, não corresponde propriamente nenhum dado laboratorial (nem sequer no caso dos cães que foram submetidos à experiência do condicionamento), ${ }^{50}$ mas antes uma interpretação desses dados à luz de uma construção do real inspirada por postulados atomistas. Aquela teoria releva, acima de tudo, de uma fisiologia imaginária, ${ }^{51}$ apoiada num associacionismo artificial, desadequado para a explicação psicológica dos comportamentos humanos.

A fisiologia viva do sistema nervoso só pode ser conhecida partindo dos dados fenomenais, ou seja, da experiência concreta da perceção, em que as coisas são vistas em função do «para que» servem, do seu meio, das condições que determinam a sua origem, das relações de coexistência com as outras, do seu possuidor, etc. Delfim Santos salienta a grande importância para a pedagogia desta análise fenomenológica da estrutura da perceção. A aprendizagem não se faz apenas por tentativas e erros (nem mesmo nas espécies animais inferiores) e uma reação útil nem sempre é fixada como o único comportamento eficaz. ${ }^{52}$ Aprender não será nunca, conclui o autor português apoiando-se em

\footnotetext{
${ }^{48}$ Relativamente à criação de uma ordem temporal especificamente humana, Delfim Santos refere a importância das investigações husserlianas sobre a consciência do tempo, que considera, em 1946, o mais significativo estudo do século XX acerca do assunto (OC II, 469).

${ }^{49} \mathrm{OC} \Pi, 471$.

${ }^{50} \mathrm{OC}$ II, 471 .

${ }^{51}$ OC II, 472.

$\$ 2$ OC II, 475 .
} 
Koffka, tornar-se capaz de repetir os mesmos gestos, mas sim fornecer a uma situação a resposta adequada por diferentes meios.

Ao cruzar-se com o pensamento existencial, porém, Delfim Santos reterá ainda a lição que aprendera em Hartmann e que já expusera em Da Filosofia e em Conhecimento e Realidade: o real articula-se em níveis diferentes, possuindo cada um deles a sua estrutura categorial própria. Nesta ordem de ideias, uma pedagogia existencial deverá iniciar-se pelo reconhecimento do momento fáctico de que depende a existência humana, a saber, o ser-no-mundo. O horizonte da atividade humana é o tempo, ${ }^{53}$ de-modo que educar não é propiciar uma fuga ao tempo, mas sim orientar o homem nas situações concretas da sua existência.

\begin{abstract}
Delfim Santos was not a phenomenologist, but his interest concerning phenomenological issues was more than an accident. Familiar with the philosophy of the Vienna Circle, but above all strongly influenced by Nicolai Hartmann, Delfim Santos sees in Husserl's phenomenology (mainly in Ideas $I$ ) the recognition of several kinds or regions of objectivity, each with its peculiar regional essence. At the same time, he looks at the theory of intentionality as acknowledging the necessary relation between any realm of reality that requests thinking activity, and reality itself recognize by thought regarding its ultimate layers of sense. But in this paper, we also show that while addressing existential issues, Delfim Santos came to the careful study Heidegger's Being and Time; man appears to him as a being determined in his terrestrial life-course by transcendence and, consequently, as in the case of the German philosopher, as belonging to a zone of reality inaccessible to traditional ontological categories. At last, we trace the marks of Merleau-Ponty (as well as Gestaltpsychology) in Delfim Santos' pedagogical works, particularly in the way he characterizes human action and its relations to physical-chemical stimuli that act not as a cause, but as a motive or occasion for meaningful behavior.
\end{abstract}

${ }^{53}$ OC II, 494. 